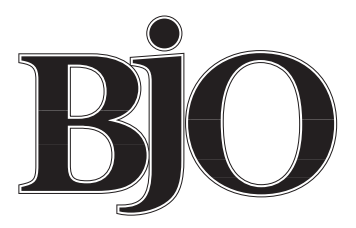

British Journal of Ophthalmology

\title{
Editorials
}

\section{The BfO goes full text on the web; www.bjophthalmol.com}

According to Declan Butler, writing in Nature $^{1}$ earlier this year, the way scientists and clinicians obtain information will radically change as more journals move over to a full electronic format. Indeed, this will alter the nature and organisation of libraries and scientific archives such that researchers will gather information from their PCs and not set foot in the

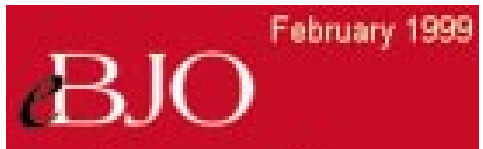
Search for artides Collected resources

Customised @lerts

Medline

About BJO

Instructions to Contributors
View current issue Browse the archive

library at all. In fact,

this is already happening as more and more readers obtain their reference sources by downloading abstracts and whole articles from literature databanks such as Medline and BIDS. Subscribers to many journals now have the choice of either or both hard copy and electronic format. Indications are that the latter is rapidly becoming the preferred option. The impact is enormous not only on how scientific information is retrieved and handled but on how libraries themselves operate. According to Butler, one university library in Denmark has already dispensed with hard copy altogether and only deals in electronic journals.

Obviously the extent to which this works for the scientific community is limited by the number of journals available on the web. Only a few years ago there were fewer than 100 journals online. Now there are thousands with an exponential rise in the number expected to occur over the next few years. Intriguingly, acquisition of online status is not related to impact factor. Indeed, many of the "in house" journals linked to associations or colleges are as likely to go online as other mainstream journals with the consequent increase in the chance of their being cited solely because of their accessibility online.
The British fournal of Ophthalmology is now joining the ranks of full text online journals. It is doing so through the not for profit concern HighWire Press, ${ }^{2}$ a division of Stanford University's Green Library, whose aim is to "increase the output and quality of society journals" as Butler puts it. The $B \mathcal{F O}$ is one of seven specialist journals from the BMA publishing group which will go online with HighWire Press and will be joining a group of around 100 journals including the fournal of Biological Chemistry and the Proceedings of the National Academy of Sciences of the USA. HighWire Press is one of several online publishing groups which are actively promoting fundamental changes in the way journals are produced and processed and consequently how information is dealt with.

The web site for the $B \mathcal{F O}$ remains as it currently stands-www.bjophthalmol.com-and its electronic name will be $e B \mathcal{B F}$. There will be a fully searchable archive from January 1997 as well as abstracts and tables of contents from earlier issues. In addition, hypertext links with other journals with HighWire Press will be available and it is expected that similar links will be available with the huge electronic resource of the Institute for Scientific Information in the near future. There will also be "customised (a)lerts", which will automatically flag up items of interest in a specific field on request and the "collected resources" feature will permit rapid searches for material of a similar nature. For subscribers from outside the United Kingdom there will be the added advantage of having early access to the full text of the journal.

There is little doubt that progress of this type will greatly assist in coping with the volume of information that is flooding through the pages of an ever increasing number of journals. Readers, once adjusted to the new format, will find it very acceptable and remarkably simple to use. Communication, which is after all the basis of science, will once more be facilitated.

JOHN V FORRESTER

\footnotetext{
1 Butler D. The writing is on the web for science journals in print. Nature 1999;397:195-200.
}

2 About HighWire Press. highwire.stanford.edu/about.shtml 


\section{Much more than water}

The belief that the tear film is aqueous based and the ocular surface changes seen in Sjögren's syndrome are due to desiccation, cause eye care practitioners to water the dry eye. Studies show the tear film is dominated by mucin and not water. ${ }^{12}$ It is not a $7-10 \mu \mathrm{m}$ thin film, but a $30-35 \mu \mathrm{m}$ thick mucin gel. Bicarbonate may be critical to forming this gel as it is in forming the bicarbonate mucin gel that protects the stomach from autodigestion. ${ }^{3}$ The hallmark of the aqueous deficient dry eye, rose bengal staining of the conjunctiva, is not produced by desiccated cells, but is due to a deficiency in the protective mucin gel. ${ }^{4}$

The first major innovation in the treatment of the dry eye seen in Sjögren's syndrome was the introduction of preservative-free artificial tears. Although the absence of preservatives allowed frequent topical application, the improvement seen in these severe dry eyes was more the result of the elimination of toxic preservatives than increased frequency of use. Preservative-free artificial tears allowed for more frequent watering of the dry eye, but watering alone does not reverse the ocular surface changes seen in Sjögren's syndrome.

The ocular surface changes include conjunctival squamous metaplasia, loss of integrity of cell membranes and junctional structures (fluorescein staining), and loss of the integrity of the mucin layer (rose bengal staining). Rose bengal staining and squamous metaplasia are not improved by the frequent application of non-preserved preparations. ${ }^{5}$ Bicarbonate and electrolyte solutions promote recovery of barrier function and ultrastructure in damaged ocular surface cells ${ }^{6}$ and increase corneal glycogen and goblet cell density. ${ }^{7}$ These solutions, however, do not totally reverse ocular surface disease seen in Sjögren's syndrome. Even with the addition of electrolytes and bicarbonate to artificial tears, watering the dry eye is not enough.

In this issue of the journal, Tsubota and colleagues ( $p$ 390) demonstrate that the application of autologous serum improved fluorescein and rose bengal scores and squamous metaplasia. It also resulted in significant upregulation of MUC-1 in conjunctival epithelial cell cultures. The authors speculate that the epidermal growth factor (EGF), vitamin $A$, and transforming growth factor $\beta$ (TGF- $\beta$ ) found in serum represent critical components missing from the tears of patients with Sjögren's syndrome.

Certain cytokines may play an important role in the regulation of proliferation, differentiation, and maturation of the ocular surface epithelium. Other cytokines may prove harmful. ${ }^{8}$ Experimental studies demonstrate that $\mathrm{EGF}^{910}$ and hepatocyte growth factor (HGF), ${ }^{11}{ }^{12}$ which are present in human tears and secreted by the lacrimal gland, are important in corneal wound healing. Both also increase as aqueous tear production increases. TGF- $\alpha^{13}$ and TGF- $\beta^{14}$ are found in human tears. Both are probably involved in corneal epithelial cell growth and differentiation. ${ }^{15}$ Retinol, also secreted by the lacrimal gland and found in the tear film, is necessary for the maintenance of healthy ocular surface epithelium. ${ }^{16}$ Not only may the tear film of patients with Sjögren's syndrome be missing critical components, tears may actually contain substances that lead to ocular surface injury. Cytokines may be produced in or by the lacrimal gland in response to inflammation. These factors, delivered to the ocular surface by the tear fluid, may lead to inflammation of the ocular surface. mRNA for interleukins IL-1 and IL-6 has been detected in the lacrimal glands of autoimmune female MRL/lpr mice. ${ }^{17}$ Increased levels of IL-1 induce keratocyte apoptosis ${ }^{18}$ and metalloproteinases. ${ }^{19}$ IL-6 induces lymphocytic differentiation.

In Sjögren's syndrome, reflex tearing decreases with increased lymphocytic infiltration of the lacrimal gland. ${ }^{20}$ Reflex tearing flushes debris from the ocular surface, dilutes substances in the tear film, and delivers higher amounts of certain cytokines to the ocular surface. The loss of reflex tearing results in reduced tear clearance causing prolonged retention of substances in the tear film. ${ }^{21}$ It is likely that the loss of reflex tearing also results in the lack of delivery of cytokines and retinol critical to the growth and differentiation of ocular surface epithelial cells.

The upregulation of MUC-1 suggests there are substances in serum which promote reformation of the mucin gel and, therefore, resolution of rose bengal staining. Similar substances, that are important in the maintenance of the mucin gel, are probably missing in the Sjögren's dry eye.

The use of serum tears is not new. ${ }^{22}$ However, Tsubota and colleagues show it is what is in tears that counts. The presence of cytokines and retinol are critical for the growth, differentiation, and wound healing of the ocular surface. Artificial tears flush out debris, dilute substances trapped in the tear film, and increase tear clearance. They do not, however, provide all the factors critical for the maintenance and repair of the ocular surface. That the application of serum tears reverses the ocular surface changes in Sjögren's syndrome should open the door to new therapies as well as reinforce the fact that tears are much more than water.

J DANIEL NELSON

Health Partners Research Foundation and the Departments of Ophthalmology, HealthPartners Medical Group Regions Hospital, 640 Jackson Street, St Paul, MN 55101, USA and the University of Minnesota, Minneapolis, Minnesota, USA

1 Prydal JI, Artal P, Woon $\mathrm{H}$, et al. Study of human precorneal tear film thickness and structure using laser interferometry. Invest Ophthalmol Vis Sci ness and structure

2 Prydal J, Campbell F. Study of precorneal fluid thickness and structure by interferometry and confocal microscopy. Invest Ophthalmol Vis Sci 1992;33: 1996-2005.

3 Slomiany BL, Slomiany A. Role of mucus in gastric mucosal protection. $\mathcal{F}$ Physiol Pharmacol 1991;42:147-61.

4 Feenstra RPG, Tseng SCG. What is actually stained by rose bengal? Arch Ophthalmol 1992;110:984-93.

5 Nelson JD, Gordon JF. Topical fibronectin in the treatment of keratoconjunctivitis sicca. Chiron keratoconjunctivitis sicca study group. Am f Ophthalmol 1992;114:441-7.

6 Ubels J, McCartney M, Lantz W, et al. Effects of preservative-free artificial tear solutions on corneal epithelial structure and function. Arch Ophthalmol 1995;113:371-8.

7 Gilbard JP, Rossi SR. An electrolyte-based solution that increases corneal glycogen and conjunctival goblet-cell density in a rabbit model for keratoconjunctivitis sicca. Ophthalmology 1992;99:600-4.

8 Nelson J. A clinician looks at the tear film. Adv Exp Med Biol 1998;438:1-9.

9 Van Setten G. Epidermal growth factor in human tear fluid: increased release but decreased concentrations during reflex tearing. Curr Eye Res release but decr.

10 Kiatazawa T, Kinoshita S, Fujita K, et al. The mechanism of accelerated corneal epithelial healing by human epidermal growth factor. Invest Ophthalmol Vis Sci 1990;31:1773-8.

11 Ii Q, Weng J, Mohan R, et al. Hepatocyte growth factor and hepatocyte growth factor receptor in the lacrimal glands, tears, and cornea. Invest $O p h$ thalmol Vis Sci 1996;37:727-39.

12 Tervo T, Vesaluuoma M, Bennett G, et al. Tear hepatocyte growth factor (HGF) availability increases markedly after excimer laser surface ablation. Exp Eye Res 1997;64:501-4.

13 Van Sletten G, Macauley S, Humphreys-Beher M, et al. Detection of transforming growth factor-alpha mRNA in rat lacrimal glands and characterization of transforming growth factor-alpha in human tears. Invest Ophthalmol Vis Sci 1996;37:166-73.

14 Yoshino K, Rahul G, Monroy D, et al. Production and secretion of transforming growth factor beta (TGF- $\beta$ ) by the human lacrimal gland. Curr Eye Res 1996;15:615-24.

15 Sotozono C, Kinoshita S. Growth factors and cytokines in corneal wound healing. In: Nishida T, ed. Proceedings: corneal healing responses to injuries and healing. In: Nishida T, ed. Proceedings: corneal healing responses to in
refractive surgeries. Amsterdam: Kugler Publications, 1998:29-38.

16 Ubels J, Loley K, Rismondo V. Retinol secretion by the lacrimal gland. Invest Ophthalmol Vis Sci 1986;27:1261-9. 
17 Ono M, Huang Z, Wickam L, et al. Analysis of androgen receptors and cytokines in lacrimal glands of a mouse model of Sjögren's syndrome. Invest cytokines in lacrimal glands of a mo
Ophthalmol Vis Sci 1994;35:S1793.

18 Wilson S, He Y, Weng J, et al. Epithelial injury induces keratocyte apoptosis: hypothesized role for interleukin-1 system in modulation of corneal tissue organization wound healing. Exp Eye Res 1996;62:325-7.

19 Girard M, Matsubara M, Fine M. Transforming growth factor-beta and interleukin-1 modulate metalloproteinase expression in corneal stromal cells. Invest Ophthalmol Vis Sci 1991;31:2441-54.
20 Tsubota $\mathrm{K}$, Xu K, Fujihara $\mathrm{T}$, et al. Decreased reflex tearing is Tsubota K, Xu K, Fujihara $\mathrm{T}$, et al. Decreased reflex tearing is
associated with lymphocytic infiltration in lacrimal glands. F Rheum 1996;
23:313-20.

21 Barton K, Monroy D, Nava A, et al. Inflammatory cytokines in the tears of patients with ocular rosacea. Ophthalmology 1997;104:186874

22 Fox R, Chan R, Michelson J, et al. Beneficial effect of artificial tears made with autologous serum in patients with keratoconjunctivitis sicca. Arthritis Rheum 1984;27:459-61.

\section{Trends in vitreoretinal surgery — time to stop and think}

In the 25 years since the introduction of pars plana vitrectomy (PPV) into the UK, there have been dramatic changes in the surgical management of posterior segment pathology. Initially, these were largely exploratory-the new found ability to access the structures and surgical pathology of the posterior segment enabling a wide range of treatment methods previously impossible to contemplate, let alone accomplish. Control of the intraocular environment, improved delivery of internal tamponade and the design of a battery of common gauge micro instruments led rapidly to an explosion of innovative techniques.

During the past 15 years, the initial explosion has given way to a (largely) quiet revolution, with the development and refinement of established and proved methods and their direction along logical paths of treatment, in conditions which hitherto caused severe and permanent loss of sight.

The paper by Ah-Fat et al, in this issue of the $\mathrm{BfO}$ (p 396), reminds us that PPV offers an alternative to previously effective and well tried methods of treatment, as well as providing the means of treating hitherto untreatable conditions and those arising as a consequence of new techniques in other fields of eye surgery. The authors make the disturbing observation, however, that their successful development of PPV techniques (coupled no doubt with the pressures of uncertain outcomes and clinical governance) has led to other ophthalmologists referring cases to their unit in greatly increased numbers, such that the time from diagnosis to surgery has increased.

Thus, while more sophisticated surgery has improved anatomical results, there has been a concurrent increase in the proportion of rhegmatogenous retinal detachments (RRDs) in which the macula is detached at the time of operation, with (possibly) a detrimental effect on visual outcomes.

A number of studies have shown that PPV, combined with internal tamponade, is effective in the treatment of RRDs, ${ }^{1-3}$ particularly those with complex retinal breaks and especially in pseudophakic and aphakic eyes. Similarly, it is generally acknowledged that PPV, combined with adjunctive techniques and various forms of internal tamponade, is effective in the surgical management of proliferative fibrovascular ${ }^{4}$ and fibrocellular disease, ${ }^{6}{ }^{7}$ macular holes, ${ }^{8-10}$ and dropped lens nuclei. ${ }^{11}{ }^{12}$ Its role in the management of age related macular degeneration (ARMD) is much less clear and the value of surgical removal of subretinal neovascular membranes, ${ }^{13}{ }^{14}$ retinal pigment epithelial cell transplantation, ${ }^{15}$ and retinal translocation ${ }^{16}{ }^{17}$ has yet to be proved.

The results of the study by Ah-Fat et al serve to highlight one of the pitfalls encountered when attempting to evaluate improvements in health care by looking only at a narrow spectrum of outcome measures. They also demonstrate the dangers of becoming a victim of one's own success, or to be more accurate, patients becoming the victims of their surgeons' success. Indeed, in the case of surgery for
ARMD, one might question the wisdom of inviting publicity for a surgical method of, as yet, unproved value which will inevitably place even greater demands on an already overburdened service.

Given that clinical governance will increase the pressure on surgeons to achieve results in line with, or better than, national audit figures and that provision of resources will depend on the conduct of evidence based medicine, vitreoretinal surgeons would be well advised to contain their surgical enthusiasm and offer only well proved treatments to their patients, unless or until they have the knowledge and resources to offer them more.

The trends in vitreoretinal surgery identified by Ah-Fat et al provide a useful insight into the problems we are likely to experience in the future, in all branches of the specialty, in the face of ever increasing demands and limited resources. As it seems inevitable that expansion of the role of vitreoretinal surgery in the treatment of an ever widening range of conditions and increased tertiary referral to specialised vitreoretinal units will continue, under the watchful gaze of the National Institute for Clinical Excellence and Commission for Health Improvement, we must be ready to provide the appropriate resources.

This means that trusts must not only make available the financial wherewithal to employ more vitreoretinal surgeons and provide equipment, but they must also encourage teaching, training, and research. Only in this way can the knowledge, expertise, and spirit of inquiry be developed to ensure that new surgical methods are properly designed and evaluated before being offered to their patients. Not only is the promised consultant expansion vitally important, but high quality fellowship programmes, clinical academic appointments, and Culyer funding must all be encouraged if we are to support the training and research necessary to develop new and better vitreoretinal surgical methods for our patients in the future.

PETER K LEAVER

Moorfields Eye Hospital NHS Trust, City Road, London EC1V 2PD

1 Gartry DS, Chignell AH, Franks WA, et al. Pars plana vitrectomy for the treatment of rhegmatogenous retinal detachment uncomplicated by advanced proliferative vitreoretinopathy. Br f Ophthalmol 1993;77:199-273.

2 Hakin KN, Lavin MJ, Leaver PK. Primary vitrectomy for rhegmatogenous retinal detachment. Graefes Arch Clin Exp Ophthalmol 1993;231:344-3.

retinal detachment. Graefes Arch Clin Exp Ophthalmol 1993;231:344-3.
Sullivan PM, Luff AG, Aylward GW. Results of primary retinal Sullivan PM, Luff AG, Aylward GW. Results of primary
re-attachment surgery: a prospective audit. Eye 1997;11:869-71.

4 Aaberg TM. Clinical results in vitrectomy for diabetic traction retinal detachment. Am f Ophthalmol 1979;88:246-53.

5 Blankenship GW, Machemer R. Long-term diabetic vitrectomy results. Ophthalmology 1985;92:503-6.

6 Machemer R, Laqua H. A logical approach to the treatment of massive periretinal proliferation. Ophthalmology 1978;85:584-93.

7 Aaberg TM. Management of anterior and posterior proliferative vitreoretinopathy. XLV Edward Jackson Memorial Lecture. Am 7 Ophthalmol 1988;106:519-32.

8 Kelly NE, Wendel RT. Vitreous surgery for idiopathic macular holes: results of a pilot study. Arch Ophthalmol 1991;109:654-9.

9 Freeman WR, Azen SP, Kim JW, et al. Vitrectomy for the treatment of fullthickness Stage 3 or 4 macular holes. Arch Ophthalmol 1997;115:11-21.

10 Ezra E, Aylward GW, Gregor ZJ. Vitrectomy and autologous serum for the retreatment of full-thickness macular holes. Arch Ophthalmol 1997;115: $1276-80$. 
11 Hutton WL, Snyder WB, Vaiser A. Management of surgical dislocated intravitreal lens fragments by pars plana vitrectomy. Trans Am Acad intravitreal lens fragments by pars plan

12 Bessant DAR, Sullivan PM, Aylward GW. The management of dislocated lens material at phacoemulsification. Eye 1998;12:641-5.

13 Lambert HM, Capone A, Aaberg TM, et al. Surgical excision of sub-foveal neovascular membranes in age-related macular degeneration. $\mathrm{Am} f$ Ophthalmol 1992;113:257-62.

14 Thomas MA, Dickinson JD, Melberg NS, et al. Visual results after surgical removal of sub-foveal choroidal neovascular membranes. Ophthalmology 1994;101:1384-96.
15 Algvere PV, Berglin L, Gouras P, et al. Transplantation of fetal retinal pigment epithelium in age-related macular degeneration with sub-foveal neovascularisation. Graefes Arch Clin Exp Ophthalmol 1994;232:

16 Machemer R, Steinhorst UH. Retinal separation, retinotomy and macular relocation II: A surgical approach for age-related macular degeneration? Graefes Arch Clin Exp Ophthalmol 1993;231:635-41.

17 de Juan E, Loewenstein A, Bressler M, et al. Translocation of the retina for management of sub-foveal choroidal neovascularisation. II: A preliminary report in humans. Am f Ophthalmol 1998;125:63546.

\section{Contributors please note:}

Communications from the UK, Republic of Ireland, Australasia, Asia, Africa, Japan, and the Middle East should be sent to the Editor, British Journal of Ophthalmology, Department of Ophthalmology, University of Aberdeen, Medical School, Foresterhill, Aberdeen AB25 2ZD, Scotland, UK (Tel: 01224 663812; Fax: 01224 663832).

Communications from Western Europe, Eastern Europe, the former Soviet Union, and Scandinavia should be sent to Professor A Kijlstra, Associate editor, The Netherlands Ophthalmic Research Institute, PO Box 12141, Meibergdreef 9 , 1100 AC Amsterdam, Netherlands (Tel: +31 20 5664535; Fax: +31 20 6913401).

Communications from the USA, Canada, and South America should be sent to Professor C Hoyt, Associate editor, University of California, UCSF Ophthalmology Department, Pediatric Ophthalmology, 400 Parnassus Avenue, Room 702 A, Box 0344, San Francisco, CA 94143, USA (Tel: +415 476 1289/1921; Fax: +415 502 6468). 